\title{
Atenção Psicossocial e Gestão de Populações: Sobre os Discursos e as Práticas em Torno da Responsabilidade no Campo da Saúde Mental ${ }^{1}$
}

MARTINHO BRAGA BATISTA E SILVA*

Este artigo tem como objetivo delinear os discursos e as práticas em torno da noção de responsabilidade no campo da saúde mental, tendo em vista o processo de negociação, divisão e delegação de encargos pelo cuidado entre profissionais, familiares, usuários e membros da comunidade. A "tomada de responsabilidade do serviço pelo território" é um desses discursos. A construção de "técnicos de referência" nos Centros de Atenção Psicossocial se torna exemplar dessas mudanças. Vê-se como as práticas relativas ao engajamento, ao vínculo e à implicação são técnicas cujas funções terapêuticas e administrativas são articuladas.

Palavras-chave: Responsabilidade; saúde mental; atenção psicossocial; gestão de populações.

Recebido em: 04/04/2005.

Aprovado em 30/06/2005. 


\section{Introdução}

Assistimos a um apelo à participação no campo da Saúde Coletiva, na medida em que as diretrizes do Sistema Único de Saúde (SUS) destacam justamente a importância de a sociedade civil decidir sobre a formulação e planejamento das políticas públicas, assim como controlar a oferta e distribuição de serviços. A participação da comunidade e o controle social têm-se configurado como estratégias democráticas para romper com a tradição centralizadora do Estado brasileiro.

A partir do trabalho de campo realizado, percebe-se que, no campo da Saúde Mental, esse apelo tem assumido a forma de uma convocação à responsabilidade dos atores sociais envolvidos no cuidado. Profissionais, familiares, vizinhos e todos aqueles que cercam ou estão vinculados ao portador de transtorno mental ${ }^{2}$ são convidados, de diferentes maneiras, a tomar para si uma parcela do encargo pela assistência. As parcerias e as redes de suporte social têm sido maneiras pelas quais se procura construir outro destino social para o louco que não a internação ou o abandono.

Quando voltamos nosso olhar para o cotidiano assistencial, muitas das diretrizes governamentais assumem uma forma ambígua: se por um lado a população está sendo convidada a participar da gestão dos recursos públicos em saúde, também pode estar sendo incentivada a compartilhar responsabilidades pela assistência. Cabe a ela formular, mas também, em certa medida, executar as diretrizes das políticas públicas. Essa ambivalência - entre exercer direitos e comprometer-se com deveres - se torna ainda mais aguda quando a população beneficiada pelas políticas públicas é aquela tutelável: loucos, crianças e índios, por exemplo. O louco é considerado irresponsável (além de incapaz e perigoso) de um ponto de vista jurídico; parece que seu engajamento com essa ordem pública - ainda que democrática - é pouco intenso e que seu vínculo com esse processo paulatino de participação e responsabilização é frágil ${ }^{3}$.

A implementação dos princípios do SUS - como a descentralização da gestão, a atenção integral e a participação da comunidade - desencadeia tensos processos político-administrativos, gerando conflitos entre recursos e responsabilidades. Alguns autores da saúde pública designam por "transferência de responsabilidades para unidades locais com concentração de poder e recursos a nível central" (LUZ, 2001, p. 21)4 esse processo de descentralização da gestão, que acaba encarregando mais do que empoderando municípios, serviços e profissionais. Esse processo se atualiza na assistência pública como uma 
necessidade de compartilhar responsabilidades entre os atores e instâncias sociais, como uma tentativa de criar parcerias.

O que poderia ser tomado como uma questão gerencial, política ou "macro" bate à porta dos Centros de Atenção Psicossocial (CAPS) - serviços extra-hospitalares de saúde mental - com frequiência, pois definir a atribuição e competência de cada pessoa envolvida na assistência torna-se algo quase cotidiano quando se procura manter em comunidade um paciente psiquiátrico egresso de internação. Pode-se dizer que se encarregar pelo atendimento do doente mental na comunidade costuma depender da construção de novos recursos terapêuticos além de medicação e escuta, tais como visitas domiciliares, reuniões com a família, agenciamento de escola, trabalho, passeios...

Dividir, negociar e delegar encargos pelo cuidado entre profissionais, familiares, vizinhos e usuários tem-se transformado numa constante no cotidiano dos serviços de saúde mental, à medida que se procuram construir redes sociais de suporte ao louco: quem cuida do quê ou de quem? Do que lançar mão para lidar com os momentos de crise psicopatológica no meio de uma praça próxima ao serviço? E se a família não estiver atenta no momento, quem atende - o médico, o psicólogo, o terapeuta com quem o usuário mais simpatiza e tem proximidade? Mais do que isso, atende em nome de quê: cuidado, controle, manutenção da ordem pública, solidariedade, piedade? Quando chega o momento de tirar o passe-livre, a quem solicitar? Chamar a assistente social pode ser uma estagiária nesses casos; não cabe ao serviço se meter? Mas e se o usuário não vem ao CAPS por que não tem dinheiro para o ônibus e a família quer interná-lo?

Esses e outros impasses da atenção psicossocial ${ }^{5}$ revelam os desafios de produzir uma autonomia e uma cidadania possíveis ao louco, os dilemas de oferecer atendimento na comunidade àqueles que conhecem a internação como modo principal de tratamento e a medicação como principal técnica de alívio do sofrimento.

Com base nas contribuições de autores como Castel $(1978$; 1986) e Foucault $(1978 ; 1979)$, a pesquisa mostra que a atenção psicossocial conta justamente com uma intensa responsabilização de atores sociais pelo cuidado para alcançar tais objetivos, por meio de diferentes procedimentos de gestão articulados à terapêutica.

Em outro momento histórico, quando da instauração da psiquiatria e do asilo na França do século XVIII, a medicina tomou para si o mandato de controle 
social de alguns comportamentos desviantes. Na sociedade liberal em constituição, o Estado, a justiça e a família dividiam as responsabilidades pelo controle do louco (dentre outros personagens urbanos que representavam um desafio à ordem pública, como prostitutas, criminosos e sifilíticos), até que a medicina entrou nessa partilha, tornando o louco um doente mental passível de tutela, tendo em vista sua desimplicação com a ordem republicana, de exercício de direitos mas sujeição a deveres cívicos. O louco se transforma em alguém que necessita de proteção / cuidados e ao mesmo tempo precisa ser administrado / controlado, ou seja, fato histórico que aponta para a articulação entre a terapêutica da doença mental e a gestão dos comportamentos que desafiam a ordem pública.

Assim como no advento da psiquiatria e do asilo, as relações entre instâncias e atores sociais no sentido de encarregar-se do louco se agudizam. Entretanto, nesse momento, em vez de a medicina tomar para si o mandato social de controle e legitimar uma atuação técnica sobre o doente mental, procurase a todo custo compartilhar responsabilidades com família e comunidade, em direção a um estatuto de cidadania e um grau de autonomia possíveis ao louco.

Além de explicitar a perspectiva teórica desse estudo, é importante sublinhar que esses resultados e conclusões sobre o processo de Reforma Psiquiátrica no Brasil são fruto de uma pesquisa de campo (de cunho etnográfico) num dos serviços territoriais de saúde mental do Município do Rio de Janeiro. Ao longo de seis meses foram realizadas entrevistas semi-estruturadas com profissionais (psiquiatras, psicólogos, pedagogos e nutricionistas, entre outros), observação de reuniões semanais de equipe e leitura de registros em prontuário. Juntaram-se a esses dados qualitativos informações sobre o perfil sociodemográfico e clínico-institucional dos usuários, contidas em documentos cedidos pelo Instituto Franco Basaglia (IFB), organização não-governamental que presta assessoria aos CAPS cariocas.

Neste artigo serão apresentadas principalmente informações contidas em prontuário, através da descrição e análise dos procedimentos e expedientes da equipe para com o usuário, sua família e vizinhança. Essa escolha não é ocasional: o prontuário é justamente um documento administrativo, burocrático, no qual as informações sobre a terapêutica ganham alto teor formal. Diferentemente das reuniões e entrevistas, não é uma fala acerca da atenção psicossocial, mas um registro desse trabalho que tem peso institucional e inclusive legal - ou seja, tem uma faceta pública mais acentuada. 
Com base nos apontamentos de Lima (1995) e Vianna (2002), pesquisadores da dimensão tutelar da administração pública em relação respectivamente - aos povos indígenas e aos menores, pretende-se apresentar esse "caso clínico" como exemplar dos elementos administrativos das práticas de atenção psicossocial.

\section{A Reforma Psiquiátrica Brasileira e os Discursos acerca da Responsabilidade no Campo da Saúde Mental}

A história dos mais de 20 anos de Reforma Psiquiátrica no país vem sendo documentada por diferentes autores ${ }^{6}$. Apesar das diferentes versões, acredita-se que ao final da década de 70 o primeiro pontapé já tivesse sido dado pelo Movimento dos Trabalhadores de Saúde Mental (MTSM), mas só na década seguinte é que as primeiras experiências concretas aconteceram, na forma de serviços públicos com uma proposta de prática clínica diferenciada. Assim, apesar de o MTSM iniciar, em 1978, um movimento pela mudança da assistência psiquiátrica brasileira, muitas vezes por meio da denúncia das péssimas condições de atendimento nos asilos, apenas em 1987 um primeiro serviço público - o CAPS Luis Cerqueira, em São Paulo-SP propõe e exercita uma prática clínica dita "ampliada" com portadores de transtorno mental.

Recentemente, a partir de 2000, duas leis consolidam a direção da política de saúde mental no Brasil, no sentido da desospitalização da assistência psiquiátrica, atendimento na comunidade e respeito aos direitos humanos do paciente: a Lei Federal no 10.216, de abril de 2001, com base na famosa "Lei Paulo Delgado", sobre a extinção dos manicômios, criação de serviços substitutivos na comunidade e regulação da internação psiquiátrica compulsória; e a Lei Federal n 10.708, de julho de 2003, conhecida como "Bolsa-Auxílio", que assegura recursos financeiros que incentivam a saída de pacientes com longo tempo de internação dos hospícios para a família ou comunidade.

Pode-se dizer que a reforma diz respeito, necessariamente, a uma mudança nas políticas públicas de saúde mental, no sentido de priorizar o atendimento comunitário do paciente psiquiátrico em detrimento da internação asilar: do tratamento da doença mental no hospício para a reinserção social do usuário na comunidade. É o que alguns autores (BEZERRA JR., 1994; AMARANTE, 1996) apontam como desospitalização, a ênfase no atendimento 
comunitário como medida governamental, redirecionando os recursos no sentido da criação de serviços comunitários de saúde mental.

Dependendo da forma como esse processo de mudança políticoadministrativa venha a ocorrer - se amparado num projeto de assistência "alternativa" ou "substitutiva" aos manicômios; se voltado para a desmontagem da instituição "física" ou "simbólica" do asilo - pode vir a se tornar desassistência. Ou seja, desospitalizar pode não significar atendimento na comunidade, mas abandono: deixar o paciente psiquiátrico sem tratamento por recusar a internação como medida assistencial; não sustentar seu atendimento na comunidade com recursos técnicos suficientes.

Desta maneira, não é só o redirecionamento dos recursos assistenciais do hospício para a comunidade que é decisivo para alcançar a desinstitucionalização da loucura. $\mathrm{O}$ isolamento e a exclusão do louco da vida em sociedade são amparados por um modo de lidar com a diferença, com fenômenos que no interior de uma determinada ordem pública são considerados insensatos ou tresloucados. Assim, faz-se necessário um processo de desmontagem dos saberes que comprimem essa experiência da loucura no interior da sintomatologia da doença mental, com concomitante criação de novos modos de sociabilidade e produção de valor social.

Eis, resumidamente, as diferenças apontadas por Amarante (1996) entre desinstitucionalização, desospitalização e desassistência. É nesse sentido que a responsabilização do serviço, do profissional e do usuário é questão para a reforma: procurando evitar o abandono e a internação, diferentes atores e instâncias sociais envolvidos no cuidado são implicados no (mas também encarregados pelo) processo de desinstitucionalização da loucura.

Em alguns momentos, temos o profissional de saúde mental em foco, procura-se comprometê-lo com as transformações da assistência psiquiátrica, com o trabalho imerso em novos e instigantes encargos e recursos: acredita-se que o aumento da responsabilidade do técnico pelo processo de trabalho exerce bastante influência sobre a produção de saúde.

É como se modos de administração de recursos humanos, fortemente ligados às formulações da análise institucional, apontassem na responsabilidade, implicação e participação dos profissionais, uma linha de fuga à inércia e burocratização das instituições de saúde. O que se procura produzir é o comprometimento e engajamento do profissional no projeto reformista: 
"Ousar pensar o fim da Administração tradicional. Do taylorismo. A equipe seria coordenada, articulada a diretrizes gerais e às iniciativas de outras equipes congêneres. Não teria seus atos normatizados, não seria dirigida. Cada conjunto de trabalhadores, em um serviço, deveria responder aos problemas de sua área [...] Este estilo de gestão pressupõe uma combinação de progressiva autonomia com responsabilidades e compromissos crescentes" (CAMPOS, 1992, p. 50 - grifos nossos).

Segundo essa contribuição da análise institucional à Reforma, o profissional deve tornar-se referência de um conjunto de usuários, responsabilizando-se pela gestão dos cuidados necessários à sua saúde mental:

“O profissional, em seu papel de referência, não é responsável pela execução de todas as atividades previstas no projeto terapêutico, mas deve estar ciente e acompanhar, ainda que à distância, a evolução do paciente no curso das atividades [...] $O$ que caracteriza o papel de referência é o fato de um profissional tomar para si o encargo de planejar, acompanhar e avaliar o conjunto de ações terapêuticas que deverão potencializar o processo de reabilitação psicossocial daquele paciente cronificado. Temos a expectativa de que a responsabilização e o vínculo sejam uma das decorrências dessa forma de trabalho" (FURTADO, 2001, p. 45 - grifos nossos).

O próprio usuário da assistência psiquiátrica pública aparece nos discursos em torno da noção de responsabilidade, sendo que suas possibilidades e limites em responder enquanto agente dos próprios atos, afetos e pensamentos são objeto de debate. Há um apelo nos sentido de torná-los sujeitos da sua existência. Segundo a concepção psicanalítica lacaniana das psicoses, o sujeito deve advir como responsável pela própria condição, de modo que haja algum reposicionamento psíquico possível:

"Aceita-se com alguma facilidade que a contribuição da psicanálise para a reforma está no fato de ser ela, psicanálise, um conjunto articulado de conceitos e práticas que visam a localizar o sujeito no sofrimento de que padece e a fazê-lo advir como responsável por sua condição - o que é verdadeiro e orienta o trabalho de qualquer psicanalista que atue como 'prático' na reforma” (TENÓRIO, 2001, p. 88 - grifo nosso).

Tendo em vista os objetivos reformistas de oferecer autonomia e cidadania possíveis ao louco, pode-se dizer que essa contribuição da psicanálise 
lacaniana à Reforma sugere uma responsabilidade possível ao louco no horizonte das práticas de atenção psicossocial:

"[...] de que modo seu trabalho [do psicanalista] pode interessar às práticas da reforma psiquiátrica e da saúde mental? Se o que norteia essas práticas é fazer o sujeito atingir melhores níveis de autonomia, cidadania e contratualidade, podemos dizer que ao psicanalista cabe abrir as possibilidades para que o sujeito tome para si a responsabilidade de se situar em sua condição e, então, transformá-la até onde o que se apresenta como irredutível, ineducável, possa se dar como limite." (FIGUEIREDO, 2001, p. 81 - grifo nosso).

Mas não são apenas os componentes da clássica relação médicopaciente que compõem os discursos acerca da responsabilidade nesse campo: também a relação serviço-população conforma essa convocação à responsabilidade de atores e instâncias sociais pelo cuidado em saúde mental. O serviço é um elemento crucial, pois se quer dele a assunção de responsabilidade pelas necessidades em saúde mental de uma população adscrita a uma área geográfica, na trilha da descentralização da gestão da assistência pública. Ele deve ter atribuições gerenciais sobre uma área administrativa municipal de saúde 7 , sendo o organizador da demanda de atendimento psiquiátrico (não o executor exclusivo do cuidado), ocupando funções de maior poder decisório sobre o uso dos recursos assistenciais, mas angariando maiores encargos pelo acompanhamento e agenciamento dos problemas em saúde mental de uma população.

No Brasil, a tomada de responsabilidade pelo território é uma diretriz ligada à substituição da lógica dos serviços privados (demanda espontânea e capacidade) por uma lógica dos serviços públicos (cobertura assistencial e referência domiciliar). A partir da Portaria Federal n 336 - que aponta o CAPS como organizador da demanda em saúde mental no território - a última lógica tornou-se estatal:

"Situemos a questão: um CAPS tem capacidade limitada (cerca de quarenta a cinqüenta pacientes em atendimento diário, intensivo, e em torno de 300 a 400 matriculados, isto é, atendidos em graus muito diversos de intensidade do cuidado); já o NAPS define sua capacidade pela meta a atingir de cobertura de uma população adscrita (território), e pelo pressuposto ético da tomada de responsabilidade. Para que o contexto urbano possa tornar-se 
objeto de nossa análise, ou seja, para dar-lhe sentido na organização de serviços e na clínica, é preciso superar o modelo da demanda espontânea (que é coerente na clínica de consultórios e serviços privados), e tomar as noções de cobertura assistencial e referência domiciliar como indispensáveis. Assim, importa menos que o CAPS de Campo Grande defina sua capacidade [...] e mais o fato de que aquele seja o serviço territorial de referência para a população de tal bairro da cidade do Rio de Janeiro" (DELGADO, 1999, p. 113-114 - grifos nossos).

Essa diretriz tem como base as contribuições da experiência italiana de Reforma Psiquiátrica. Segundo Rotelli (1990), houve muita atenção para com os efeitos de capilarização do controle social produzido pelos serviços psi na comunidade, enquanto se deixava de lado o abandono gerado pelos mesmos especialismos:

“As análises sociológicas e sócio-psiquiátrica têm insistido em apontar os riscos presentes nesta difusão e especialização dos serviços psiquiátricos na comunidade: psiquiatrização dos problemas sociais e difusão capilar dos mecanismos de controle social na comunidade [...]. Mas estas preocupações deixaram de lado outros efeitos complementares a estes, ou seja, os efeitos de seleção, de falta de resposta aos problemas e sofrimentos das pessoas, de abandono" (ROTELLI, 1990, p. 22).

O lugar da responsabilização do serviço na mudança da situação criada pelas atividades profissionais especializadas, segundo o autor, é fundamental. É nesse sentido que a "tomada de responsabilidade do serviço pelo território" se torna uma diretriz, favorecendo um incremento no repertório profissional no sentido de evitar o abandono e a internação:

"Este é então outro aspecto de trabalho terapêutico entendido como 'tomar encargo' ['presa in carico' foi traduzido por "tomar encargo"; cabe ressaltar que esta expressão se constitui numa premissa fundamental na organização dos serviços territoriais e significa o 'fazer-se responsável', isto é, a impossibilidade de delegar a uma outra estrutura a assistência à população da região de referência], de cuidar de uma pessoa: é desenvolvido de tal modo a evitar o abandono do paciente a si mesmo" (ROTELLI, 1990, p. 34 - grifos nossos).

Resumindo, esses discursos em torno da responsabilidade são disseminados por diferentes saberes, sob a forma da "tomada de 
responsabilidade do serviço pelo território", do "aumento da responsabilidade do profissional sobre o processo de trabalho" e da "possibilidade de o sujeito advir como responsável pela própria condição". . Veremos ao final deste texto que esses discursos se conjugam a diferentes práticas de responsabilização de atores sociais pelo cuidado, como a mediação, a arbitragem e a negociação das ações da família e da vizinhança em relação ao usuário. Esse profissional, cuja atribuição é produzir implicação e vínculo, muitas vezes até adesão, também é objeto de práticas discursivas, como aquelas que tentam estimular seu engajamento no trabalho.

\section{O Centro de Atenção Psicossocial e as Práticas em Torno da Responsabilidade}

$\mathrm{Na}$ década de 80, algumas experiências assistenciais buscaram alternativas para a conquista de direitos por parte do paciente psiquiátrico. Uma avaliação dessas iniciativas técnico-assistenciais é apresentada por Bezerra $\mathrm{Jr}$ (1994, p. 186). Ele aponta os fracassos na ressocialização dos pacientes, tendo em vista idealizações em relação ao louco e à sociedade, pois "não havia permeabilidade no tecido social que possibilitasse a incorporação de pessoas com características muito próprias - e, do ponto de vista dominante, limitadas". Assim, a defesa do estatuto de igualdade e a inclusão social automática cederam lugar à proteção e aos mecanismos de inserção social.

Mas como acontece essa proteção? Como funcionam tais iniciativas de inserção social? Se admitirmos a necessidade de algum grau de tutela para os pacientes psiquiátricos, precisamos pensar nos mecanismos de controle e domínio que estamos acionando, pois a atividade de integrar socialmente e ressocializar está articulada e ao mesmo tempo tem autonomia em relação àquela jurídica de interditar. Ou seja, neste momento, precisamos investigar a tutela não tanto a partir de sua dimensão de estatuto jurídico, mas principalmente de exercício de controle que permite integrar socialmente:

"Cabe aos técnicos de saúde mental o 'papel tutelar' de elaborar projetos e ações práticas que modifiquem as condições concretas de vida desses usuários, incentivando-os a participar de trocas sociais e conseqüentemente aumentando o seu poder contratual e a sua autonomia" (DIAZ, 2001, p. 14 - grifo nosso). 
A atenção psicossocial envolve diferentes procedimentos, tais como "mediar as trocas sociais" do louco no sentido de aumentar sua contratualidade (TYKANORI, 1996), favorecer um maior "grau de gerenciamento de si próprio" em busca de maior autonomia (GOLDBERG, 1996) e "tornar-se referência" para garantir um vínculo de confiança e uma continuidade no atendimento (GOLDBERG, 1996). Em todas essas atividades se conjugam cuidado e administração da loucura, tendo em vista as limitações que esta impõe à existência no meio social e aos conflitos que gera na ordem pública. Inclusive, a pesquisa de campo realizada em um dos CAPS cariocas ${ }^{9}$ mostra que novos encargos sociais se conectam a novos modos de cuidar e gerir a loucura no tecido social, preferencialmente por meio do engajamento, da implicação e do vínculo de atores e instâncias sociais envolvidos no cuidado.

Em julho de 1996, abriram-se as portas desse CAPS para a população local. Em abril de 2004, esse serviço tinha mais de 400 usuários. A partir da mudança na diretriz governamental relativa aos CAPS, entre as Portarias federais $n^{\circ}$ s 224 e 336, de uma lógica da capacidade (150 usuários por serviço, no máximo), se passou a uma lógica territorial (ordenar e gerenciar a demanda e os serviços de saúde mental da população da AP). Logo, uma sobrecarga foi vivida pelos profissionais (IFB, 2003).

De menos de 100 usuários em 1998, passou-se a 429 usuários matriculados, 503 em atendimento no serviço no ano de 2004. Dentre eles, 220 se encontravam em atenção diária e 49 foram matriculados no segundo semestre de 2002. O lugar do serviço como agenciador do cuidado ao usuário - o encargo de gerenciamento da atenção em saúde mental da população local - não impediu o serviço de ocupar lugar de principal agente desse cuidado - responsabilizandose pela execução do cuidado - que ultrapassou seus limites:

"O ano foi percorrido por intensos debates em torno, principalmente, do excessivo número de usuários atendidos no CAPS (em dezembro de 2002 totalizando 503). Esta difícil situação gerou sobrecarga de trabalho para a equipe, ocupou parte do tempo da supervisão na tentativa de encontrar soluções que implicavam, na verdade, em ações do restante da rede de assistência da Área [...]” (IFB, 2003, p. 62).

A partir dos impasses que o serviço encontrava, uma reorganização dos processos de trabalho em equipe ganha destaque, contando com a noção de Técnico de Referência - TR e de Projeto Terapêutico Individual - PTI 
(IFB, 2003, p. 60). Esses dois dispositivos são importantes elementos produtores de implicação, engajamento, comprometimento e participação entre os atores sociais envolvidos no cuidado - profissionais, mas também familiares, usuários e eventuais membros da comunidade. Pode-se dizer que a constituição de "referências" e "contratos" se tornaram estratégias privilegiadas para lidar com os novos encargos - de gestão de populações - nos CAPS. É nesse sentido que se torna inteligível uma das recomendações para a supervisão em 2003, no que tange às estratégias clínico-políticas, que nos acompanhará ao longo das linhas abaixo:

"Projeto Terapêutico Individual e o Técnico de Referência: avançar na discussão/teorização sobre papel do 'TR': qual a concepção de clínica que subjaz à noção do TR? Como se constrói a 'referência'? Trabalhar as noções de vínculo, mediação, transferência, co-responsabilidade, suporte; valorização do encontro com os familiares; importância de registro no prontuário das ações desenvolvidas; o PTI como dispositivo de 'visibilização' do usuário" (IFB, 2003, p. 74 - grifos nossos).

A dicotomia entre um papel de gestão dos encaminhamentos e o de atendimento contínuo ao paciente percorrerá boa parte do debate sobre TR nas reuniões de equipe. Por um lado, aparece a figura do "catalisador", gerente das ações de cuidado; por outro, a figura do "clínico", aquele que intervém no momento em que a demanda surge.

Essa dicotomia se desdobra em outra: entre aqueles que "atendem" e aqueles que "fazem reunião". Tendo em vista a "enxurrada" de encaminhamentos ao serviço e a "tomada de responsabilidade pelo território" como diretriz assumida pelos CAPS, o serviço optou por tomar esse encargo em conjunto com os demais serviços da rede de saúde, procurando engajá-los nos atendimentos aos pacientes menos graves por meio de reuniões (IFB, 2003). Entretanto, um dilema se instaurou: como conciliar o tempo de serviço entre atendimentos e reuniões, entre estar com o usuário e estar com os outros serviços que colaboram para o acompanhamento de usuários menos graves:

"Eu também acho ruim esse negócio de ficar enchendo o serviço de quinhentas atribuições quando tem muita gente para ser atendida [...]. Às vezes ficam os profissionais aqui do CAPS fazendo quinhentas reuniões para achar buraco numa rede que está saturada, absolutamente saturada" (psiquiatra). 
No decorrer da pesquisa de campo, quando perguntamos a uma psicóloga sobre a atividade de compartilhar tarefas, se há algum caso em que há necessidade de agir em conjunto, escutamos: "A grande maioria deles, TR é justamente esse articulador [...] o TR é esse que vai estar estruturando várias frentes de intervenção". Cita um exemplo, no qual houve uma parceria com a família e a escola, tendo em vista o diagnóstico de deficiência mental. Pela via de um contrato com a coordenadora pedagógica, houve a tentativa de manter o paciente numa escola comum, de modo que ficasse "menos dependente da mãe".

Um dos técnicos chega a sugerir que o técnico de referência seria uma nova especialidade em Saúde Mental, "um modo de fazer a clínica, como a Psicologia, a Psiquiatria, a oficina" (auxiliar de enfermagem). Além disso, sugere uma ligação entre a figura do técnico de referência e "se adequar à Saúde Mental". Ele acrescenta:

"O técnico de referência pode se tornar um profissional, fazer visita domiciliar, acompanhamento terapêutico [...]. Vai existir um técnico de referência como existe hoje o enfermeiro, o médico [o profissional] vai ficar circulando com o paciente" (auxiliar de enfermagem - grifo nosso).

Mas o que realiza esse técnico de referência, que reúne em si o papel de agente e agenciador do cuidado?

Para responder a essa pergunta, vamos nos dedicar exclusivamente ao atendimento "psicossocial" de um portador de transtorno mental, pelo fato de ele reunir em sua trajetória clínico-institucional elementos exemplares do processo de negociação, divisão e delegação de encargos entre profissionais, usuários, familiares e membros da comunidade. Sandro (nome fictício, como todos os demais aqui citados), usuário do serviço desde 1996, aponta questões extremamente emblemáticas dos desafios desses serviços de atenção psicossocial no território, com seus encargos angustiantes e ao mesmo tempo recursos inusitados, com suas tecnologia de cuidado, mas também de controle. Mais do que nunca, é o teor administrativo das decisões no atendimento ao usuário que se destaca a seguir.

Sandro, 35 anos, foi descrito da seguinte forma quando chegou ao serviço, em agosto de 1996:

"Vive sozinho, veio trazido pela tia Carla, irmã do pai. Vivia na rua, dormia no prédio do CAPS, quando era LBA. Pais o rejeitaram, deixando com avós 
paternos dos 6 aos 11 anos. Avós faleceram. Ficou com tia Carla até 18 anos. Marido não aceitou e então Sandro passou a viver na rua.” (prontuário).

Não há registro de que fora internado até então, mas consta que desde os 11 anos apresenta alucinação visual, agressão e depressão. Esteve preso em 1994, ficando três meses na cadeia (hipótese de tentativa de furto). Sandro recebe atendimento médico em grupo e individual, visitas domiciliares e participa de oficinas em seu tratamento: eis o seu "projeto terapêutico".

Constam também informações sobre a rede social de suporte: "Almoça na casa de D. Senira" (prontuário). Logo nos primeiros meses de atendimento, a participação dos parentes e vizinhos se coloca, fazendo parte freqüentemente de seu registro em prontuário "reuniões com a família" ou com membros da comunidade. Consta que o "tio de Sandro (Sr. Santos) veio queixar-se que o paciente passa a noite em bailes e não faz uso da medicação" (prontuário).

Duas figuras se destacam no atendimento de Sandro: D. Senira, senhora conhecida, em cuja casa ele costuma jantar, almoçar, tomar banho e, às vezes, dormir. Ao mesmo tempo é um membro da comunidade, citado em prontuário, que remete a um recurso comunitário que pode ser acionado, além de ser também um local, uma casa, algo onde alocar. Em se tratando de um usuário que oscila entre a rua, a internação e a casa, com freqüência optando pela primeira em sua vida, essa questão do lugar onde ficar se torna relevante. Além disso, Tia Carla também é bastante citada, é onde Sandro costuma dormir.

Em outubro daquele ano, consta que Sandro trabalhava como "faxina" em um trailer de cachorro-quente, na madrugada. Além disso, Sandro costuma "chantagear" o serviço, ameaçando profissionais com a afirmação de que "vai virar bandido", "fogueteiro [do tráfico]". Em dezembro, a atuação dos profissionais junto a familiares e membros da comunidade começa a ser descrita de modo mais extenso e detalhado. A atitude de mediação das relações parece se destacar, no sentido de manter o usuário em uma rede social de cuidado. Assim, lê-se:

"D. Senira traz uma série de queixas sobre S., falando da dificuldade deste em chegar no horário do jantar, chegando às vezes 22 horas. Ao mesmo tempo, D. Senira demonstra uma enorme dificuldade em colocar limites no Sandro que consegue muitas coisas através de atitudes sedutoras e às vezes fazendo chantagem como 'vou virar bandido'. Foi pontuada a importância da presença de limites para favorecer [...]. Através de 'contratos' estabele- 
cem-se limites como de Sandro chegar no horário da refeição, do banho etc. Senira fica muito mobilizada, demonstrando linguagem ambígua quando perguntado o que faria caso Sandro chegue atrasado. Pontuamos que é importante que não só o Sandro mas D. Senira também cumprir contratos" (prontuário - grifo nosso).

As categorias "limite" e "contrato" delineiam a atuação técnica. Através da criação de "acordos", procura-se produzir uma relação menos conflituosa entre membros da comunidade e usuário, tendo em vista a atitude pouco disponível a cumprir regras por parte do segundo.

No ano seguinte, em maio de 1998, "Dois moradores da área procuraram a unidade para queixar-se do paciente. $\mathrm{O}$ dono da padaria [...] o cunhado de Carla, sua tia, diz...". Acusam-no de urinar em frente à padaria e de possível furto dos próprios amigos. Logo em seguida, em agosto, aparece uma situação limite no atendimento: não ter com quem ficar, não ter quem cuide e controle, quem se responsabilize por Sandro. A partir daí, tecnologias de regulação social aparecem, como a mediação e a arbitragem, no sentido de produzir responsáveis pelo cuidado e alocar indivíduos em redes de relações. Assim, lê-se:

"D. Senira e D. Carla participaram de atendimento. Colocou-se para Sandro a importância em seguir os limites colocados pois hoje chegou às 10:40 horas no CAPS e fizemos o acordo de que ele não poderia ficar na unidade no dia que chegasse nesse horário. Carla coloca que a partir das dificuldades que surgiram com Sandro a opção foi de não morar com ele, porém se mostrou disponível para participar uma vez por mês do atendimento. D. Senira fala que Sandro tem respeitado o horário estabelecido. Falamos da importância disso e também combinamos que Carla contactaria a assistente social da FUNLAR para Sandro fazer o curso profissionalizante” (prontuário).

Abandonado pela tia e morando com uma conhecida, Sandro é instigado a participar de um curso profissionalizante. Desse modo, da inserção na rede social imediata, familiar, passa-se à inserção social na rede imaginada como nacional, o Estado, pela via do trabalho. Além disso, quem se responsabiliza por agenciar tal contrato? Curiosamente, é o familiar que acabou de se desresponsabilizar pelo cuidado contínuo do usuário. Passar de agente do cuidado a agenciador de possibilidades de existência acontece não só com os profissionais, mas também com os familiares. O que parece importar é manter o vínculo, a rede de relações. Nesse momento, registra o profissional encarregado do caso: 
"Fui procurada pela tia de Sandro, Carla, que me informou que a partir do final deste mês, Sandro terá que deixar o quarto onde reside pois o mesmo será ocupado por ela. Nos dirigimos então à residência de D. Senira para em conjunto pensarmos e buscarmos alternativas na comunidade para solucionar a questão da moradia para Sandro Fiz também contato telefônico com Zilda [técnica] do CPP II, responsável pelo lar abrigado feminino que se prontificou em sondar possibilidades para o mesmo na instituição” (prontuário).

Dias depois, consta que um chefe de serviço de moradia em hospital psiquiátrico "informa que Sandro não tem perfil para lar abrigado" (prontuário). Novamente, trata-se de tentativas de engajar, de comprometer, de implicar atores sociais no cuidado. O CAPS se coloca em posição bastante difícil de ser sustentada no atendimento de Sandro, que é a de mediar a relação dele com diferentes atores e instâncias sociais. Será que esses procedimentos envolvem alocação de indivíduos em redes de relação social, por meio da produção de responsáveis pelo cuidado?

"Carla traz sua preocupação com a possibilidade de Sandro morar com ela e o marido, por conta de determinadas regras que o marido (S. Luís) impõe. Sandro inicialmente parece não querer posicionar-se e traz novamente como opção trabalhar no tráfico. Deixamos bem claro para Sandro que este tipo de opção não terá apoio da equipe. Sandro permanece quase o tempo todo calado, e ao final da reunião posiciona-se para morar na rua - guardaria seus objetos na D. Senira (já teria combinado com ela)” (prontuário).

A rua, a internação e o tráfico de drogas apresentam-se como situações intoleráveis pelo serviço, de modo que se tenta a todo custo construir uma solução possível e aceitável (do ponto de vista moral?). E isso se faz por meio de uma gestão da "comunidade", de técnicas de mediação e arbitragem. Uma complexa rede de relações e uma diversidade de atores e instâncias sociais compõem uma espécie de malha administrativa em torno do usuário. O relato a seguir, na verdade, levanta mais perguntas do que as articulações teóricas permitem responder. Esse precioso documento é um convite às questões que a atenção psicossocial oferece aos estudos sobre a atividade comunitária em saúde.

"Fui procurada por Carla, que me comunicou que o proprietário do quarto, no qual Sandro poderia morar, foi procurado pelo mesmo, porém não compreende as informações que Sandro lhe passou e que já havíamos acordado na reunião para a abertura da negociação a respeito da moradia. Solicitei 
então que Sandro trouxesse à unidade este senhor para iniciarmos as negociações em conjunto, já que o mesmo negou ajuda da sua tia Carla. O senhor Gilson aceitou acolher Sandro e Sandro se comprometeu a pagar com seu ganho de trabalho no trailer, mais o valor autorizado por sua tia Carla de R $\$$ 10,00 e mais a cesta básica fornecida pelo CAPS. O Sr. Gilson solicitou a doação de 50 tijolos e dois sacos de cimento, que serão negociados junto à associação por outra profissional que participou também das negociações. Sandro se comprometeu também em trabalhar como o Sr. Gilson, numa serralheria que o mesmo pretende montar futuramente. Foi dado a Sandro o tíquete da cesta básica, para ser entregue ao Sr. Gilson [...]. Será oferecida uma vaga no curso de marcenaria para o Sr. Gilson" (prontuário - grifos nossos).

Imagino que a descrição do trabalho de muitos outros profissionais como os assistentes sociais - poderia colaborar para investigar as tecnologias psicossociais descritas acima, assim como as atividades nos grupos de família poderiam indicar mais caminhos de investigação de técnicas de implicação do usuário no tratamento, pela via da responsabilização dos familiares ou do comprometimento de membros da comunidade. Através desses registros, entretanto, podemos ter um esboço das modalidades de exercício de poder acionadas nos CAPS, em que as trocas, recursos e encargos entre o Sr. Gilson, Sandro e os profissionais do serviço nos fazem perguntar sobre o objeto das mediações e negociações das quais temos falado: a arbitragem - mediar conflitos no sentido de adquirir poder de decidir e intervir sobre uma rede de relações sociais - atinge Sandro ou o Sr. Gilson? Quem está sendo gerido nesse processo complexo de engajamento e produção de vínculo com atores sociais?

\section{Conclusão}

Podemos concluir, desta maneira, que a "tomada de responsabilidade pelo território", o "aumento da responsabilidade do profissional pelo processo de trabalho" e a "possibilidade de o sujeito advir como responsável pela própria condição" são um conjunto de discursos que operacionalizam essa convocação à responsabilidade. Eles estão ligados à saúde pública, à análise institucional e à psicanálise, com incidência tanto sobre a prática psi de atendimento individual, quanto sobre a organização dos serviços e a gestão de recursos humanos. Assim, alguns saberes do campo da Saúde Mental, que costumam deter 
concepções diferentes e muitas vezes contraditórias do fenômeno psiquiátrico, convergem no sentido de apontar a responsabilização de atores e instâncias sociais como caminho no sentido da desinstitucionalização da assistência psiquiátrica.

De modo mais esparso, sem que assumam a forma de prática discursiva, algumas formulações procuram responsabilizar não só serviços, profissionais e usuários, mas também a comunidade, através do estabelecimento de "parcerias" e "co-responsabilidades". Além disso, não podemos nos esquecer de que cabe justamente ao Estado, a partir da Constituição de 1988, a responsabilidade pelas condições de saúde da população: "a saúde é um direito do cidadão e um dever do Estado".

Nos serviços territoriais de saúde mental, Centros de Atenção Psicossocial (CAPS) no Município do Rio de Janeiro, profissionais acionam práticas em torno da noção de responsabilidade. A atenção psicossocial é uma atividade que conta com a contribuição de diferentes saberes e profissionais, como também do saber leigo (mas nem sempre laico) dos familiares e da comunidade. O principal objetivo dessa modalidade terapêutica é aumentar as possibilidades de existência do louco no tecido social, ao mesmo tempo em que procura minimizar o sofrimento psíquico. Para tanto, cuida-se do usuário, convocando à responsabilidade aqueles que o cercam, no sentido de que a dependência institucional diminua e os "laços sociais" aumentem. Paulatinamente, procura-se "engajar", "implicar" e "vincular" atores sociais diversos na tarefa de cuidar. Familiares, vizinhos e profissionais são convidados a participar da assistência psiquiátrica, apresentando dificuldades em tomar para si encargos sobre o cuidado e, de certa forma, estando pouco à vontade para exercer gerência sobre os recursos.

Pode-se afirmar que discursos e práticas em torno da responsabilidade estão sendo configurados no campo da Saúde Mental, no sentido de formular instrumentos e técnicas eficazes para manter em comunidade pacientes psiquiátricos egressos de internação.

\section{Referências}

AMARANTE, P. O homem e a serpente: histórias sobre a loucura e a psiquiatria. Rio de Janeiro: FIOCRUZ, 1996. 
. Loucos pela vida: a trajetória da reforma psiquiátrica no Brasil. Rio de Janeiro: FIOCRUZ, 1995.

BEZERRA JUNIOR., B. De médico, de louco e de todo mundo um pouco. In: GUIMARÃES, R.; TAVARES, R. (Orgs.). Saúde e sociedade no Brasil: anos 80. Rio de Janeiro: Relume-Dumará, 1994. p. 171-191.

BIRMAN, J. A cidadania tresloucada: notas introdutórias sobre a cidadania dos doentes mentais. In: BEZERRA JUNIOR, B.; AMARANTE, P. (Orgs.). Psiquiatria sem hospício: contribuições ao estudo da reforma psiquiátrica. Rio de Janeiro: Relume-Dumará, 1992. p. 71-90.

CAMPOS, F. B. Considerações sobre o movimento de reforma dos serviços de saúde mental. In: . Psicologia e saúde: repensando práticas. São Paulo: Hucitec, 1992. p. 59-64.

BRASIL. Ministério da Saúde. Legislação em saúde mental: 1990-2004, Brasília: Ministério da Saúde, 2004.

CASTEL, R. A gestão dos riscos: da antipsiquiatria à pós-psicanálise. Rio de Janeiro: Francisco Alves, 1986.

A ordem psiquiátrica: a idade de ouro do alienismo. Rio de Janeiro: Graal, 1978.

COSTA-ROSA, A. et al. Atenção psicossocial: rumo a um novo paradigma na saúde mental coletiva. In: AMARANTE, P. (Org.). Archivos de saúde mental e atenção psicossocial, Rio de Janeiro: Nau, 2002. p. 13-44.

DELGADO, P. Atendimento psicossocial na metrópole: algumas questões iniciais. Cadernos do IPUB, Rio de Janeiro, n. 14, p. 113-122, 1999.

DIAZ, F. "Loucos de todo gênero são incapazes": justiça e saúde mental no município de Angra dos Reis na década de 90. 2001. Dissertação (Mestrado em Saúde Coletiva) - Instituto de Medicina Social, Universidade do Estado do Rio de Janeiro, Rio de Janeiro, 2001.

FIGUEIREDO, A. C. O que faz um psicanalista na Saúde Mental. In: VENÂNCIO, A. T.; CAVALCANTI, M. (Orgs.). Saúde mental: campo, saberes e discursos. Rio de Janeiro: IPUB/CUCA, 2001. p.73-82.

FOUCAULT, M. A história da loucura na idade clássica. Rio de Janeiro: Perspectiva, 1978. Microfísica do poder. Rio de Janeiro: Graal, 1979. 
FURTADO, J. Responsabilização e vínculo no tratamento de pacientes cronificados: da unidade de reabilitação de moradores ao CAPS Estação. In: HARARI, A.; VALENTINI, W. (Orgs.). A reforma psiquiátrica no cotidiano. São Paulo: Hucitec, 2001. p. 37-58.

GOLDBERG, J. Reabilitação como processo: o Centro de Atenção Psicossocial. In: PITTA, A. (Org.). Reabilitação psicossocial no Brasil. São Paulo: Hucitec, 1996. p. 33-47.

GOMES, M.; ALBUQUERQUE, P. Políticas públicas de saúde e saúde mental: um desafio. In: IPUB. Cadernos do IPUB 60 anos. Rio de Janeiro: IPUBUFRJ, 1998. p. 62-72.

GOMES, M. A Política pública de saúde mental na cidade do Rio de Janeiro. 1999. Tese (Doutorado em Psiquiatria)-Instituto de Psiquiatria, Universidade Federal do Rio de Janeiro, Rio de Janeiro, 1999.

INSTITUTO FRANCO BASAGLIA. Relatórios de Assessoria Técnica do Convênio IFB-CAPS-SMS/RJ. Rio de Janeiro: IFB, 2003.

LIMA, A. Um grande cerco de paz: poder tutelar, indianidade e formação do Estado no Brasil. Petrópolis: Vozes, 1995.

LOURAU, R. A análise institucional. Petrópolis: Vozes, 1975.

LUZ, M. T. Políticas de descentralização e cidadania: novas práticas de saúde no Brasil atual. In: PINHEIRO, R.; MATTOS, R. A. (Orgs.). Os sentidos da integralidade na atenção e no cuidado à saúde. Rio de Janeiro: IMS/UERJ, 2001.p. 17-38.

ROTELLI, F. et al. Desinstitucionalização, uma outra via: a reforma psiquiátrica italiana no contexto da Europa Ocidental e dos "países avançados". In: NICÁCIO, F. (Org.). Desinstitucionalização. São Paulo: Hucitec, 1990. p. 17-59.

SILVA, M. Responsabilidade e reforma psiquiátrica brasileira: sobre a produção de engajamento, implicação e vínculo nas práticas de atenção psicossocial. 2004. Dissertação (Mestrado em Saúde Coletiva)-Instituto de Medicina Social, Universidade do Estado do Rio de Janeiro, Rio de Janeiro, 2004.

TENÓRIO, F. Reforma psiquiátrica e psicanálise: um trabalho necessário. In: FIGUEIREDO, A.; CAVALCANTI, M. (Orgs.). A reforma psiquiátrica $e$ 
os desafios da desinstitucionalização.Rio de Janeiro: IPUB/CUCA, 2001. p. 69-84.

TYKANORI, R. Contratualidade e reabilitação psicossocial. In: PITTA, A. (Org.). Reabilitação psicossocial no Brasil. São Paulo: Hucitec, 1996. p. 5559.

VASCONCELOS, E. Saúde mental e serviço social: o desafio da subjetividade e da interdisciplinaridade. Rio de Janeiro: Cortez, 2001.

VIANNA, A. Os limites da menoridade: responsabilidade, tutela e família em julgamento. Tese (Doutorado em Antropologia Social)-Programa de Pósgraduação em Antropologia Social, Universidade Federal do Rio de Janeiro, Rio de Janeiro, 2002.

\section{NOTAS}

* Mestre em Saúde Coletiva pelo Programa de Pós-graduação em Saúde Coletiva do IMS-UERJ; psicólogo do Centro de Atenção Psicossocial Lima Barreto (Bangu, Rio de Janeiro). Endereço eletrônico: martinho02003@yahoo.com.br.

${ }^{1}$ Este texto é um resumo da dissertação de mestrado, defendida em abril de 2004 no Instituto de Medicina Social da UERJ, sob orientação do prof. Sérgio Carrara, intitulada Responsabilidade e Reforma Psiquiátrica Brasileira: sobre a produção de engajamento, implicação e vínculo nas práticas de atenção psicossocial.

${ }^{2}$ Usuário de serviço de saúde mental, paciente psiquiátrico, doente mental, louco, psicótico e portador de sofrimento psíquico intenso são algumas das terminologias utilizadas para designar aquelas pessoas em tratamento psiquiátrico na rede pública. Embora cada uma delas reflita uma determinada concepção teórica do fenômeno da loucura e política da assistência pública em saúde, não pretendemos cansar o leitor utilizando apenas um dos termos, de modo que os utilizaremos alternadamente. Entretanto, segundo nossa concepção teórica, o termo louco é mais apropriado pelo fato de ser uma categoria relativa a uma experiência existencial e histórica mais abrangente que a doença mental.

${ }^{3}$ Castel (1978, p. 36) indica elementos no sentido dessa formulação: "Não obstante, apesar de seu caráter formal, nem todos os súditos da república entram sem problema nesse quadro contratual. A verdadeira especificidade do louco é a de resistir a essa redução, a tal ponto que, para inscrevê-lo na nova ordem social, será preciso impor-lhe um estatuto diferente e complementar àquele, contratual, que rege a totalidade dos cidadãos”. 
${ }^{4}$ Luz (2001) aponta essa disparidade entre atribuições, competências e recursos como principal dificuldade à implementação do SUS no Brasil, em um contexto sócio-histórico de neoliberalismo mundial. Além disso, segundo a autora, no processo de redemocratização das instituições públicas no país a sociedade civil se tornou importante ator social; entretanto, tendo em vista mudanças globais de cunho econômico e político, ela passa a adquirir encargos pela própria execução das políticas públicas. Gomes e Albuquerque (1998, p. 122) também destacam esse fenômeno no campo da Saúde Mental.

${ }^{5}$ Clínica Ampliada, ressocialização, reabilitação psicossocial e clínica da Reforma são algumas das maneiras pelas quais se designam as práticas assistenciais concretas de atendimento ao paciente psiquiátrico. Optamos por atenção psicossocial (VENÂNCIO et. al., 1997; COSTAROSA, 2001), pois o termo está ligado ao caráter de atividade não exclusivamente médica e necessariamente pública das práticas.

${ }^{6}$ Também designaremos por Reforma Psiquiátrica e com mais freqüência por Reforma ou $\mathrm{RPb}$ o processo histórico de transformação da representação social, do modelo de atenção e da política pública de Saúde Mental no Brasil, em curso desde a década de 70. Há textos que se tornaram clássicos, como os de Amarante (1995; 1997); há também atualizações recentes como as de Tenório (2001) e Vasconcelos (2001) - e outros autores igualmente relevantes para a descrição abrangente do processo de Reforma, como é o caso de Delgado (1992) e Bezerra Jr. (1994).

${ }^{7}$ O Município do Rio de Janeiro foi regionalizado em áreas programáticas (AP), para efeito de organização de serviços de saúde, sendo que cada uma delas é composta de um conjunto de bairros adjacentes (SMS-RJ, 1999). Quando se fala de "tomada de responsabilidade do serviço pelo território", o serviço comunitário de saúde mental deve ter como encargo justamente a população de uma A.P., ocupando o lugar de organizador e gerenciador da demanda por atendimento (Portaria Federal no 336).

${ }^{8}$ Não é desnecessário lembrar que existe uma especificidade dessas formulações em cada um dos saberes institucionalizados. Na análise institucional, por exemplo, a idéia de implicação é uma tentativa de romper com o utilitarismo da idéia de estímulo à participação (LOURAU, 1975), com o qual o aumento da autonomia e responsabilidade pelo processo de trabalho nas equipes de saúde pode se confundir (CAMPOS, 1997). Além disso, responsabilizar o sujeito para remeter a um chamado ao sujeito do inconsciente, como se o analisando fosse instigado a situar sua posição subjetiva em atos aparentemente voluntários, algo diferente, portanto, de culpabilizar o indivíduo. O que procuramos destacar é a articulação dessas recomendações técnicas em um bloco, reunindo e condensando sentidos e formando palavras de ordem, algo 
comum no campo da Saúde Pública, como Camargo Jr. (2001) demonstra em relação à idéia de "integralidade" na atenção e no cuidado.

${ }^{9}$ Não se poderia dizer que esse serviço é representativo dos CAPS cariocas, quanto mais do Brasil, já que cada um desses serviços territoriais tem suas particularidades, com processos de implantação na comunidade muito diversos. Entretanto, essas peculiaridades não sugerem que os procedimentos de gestão da loucura aqui descritos sejam "problema dessa equipe" ou "culpa dos técnicos", já que estão integrados às recomendações da própria política municipal e federal de saúde mental, como esperamos ter demonstrado ao apresentar os discursos em torno da responsabilidade. 


\section{ABSTRACT}

\section{Psychosocial Care and Population Management: discourses and practices concerning responsibility in mental health}

This article aims to demarcate the discourses and practices concerning the notion of responsibility in the field of mental health, given the process of negotiating, sharing, and delegating responsibilities for care between healthcare professionals, family, clients, and community members. "Taking responsibility for the service through the territory" is one such discourse. The construction of "reference staff members" in Centers for Psychosocial Care is an example of such changes. One notes how practices pertaining to engagement, bond, and implication are techniques whose therapeutic and administrative functions are linked.

Key words: Responsibility; mental health; psychosocial care; population management. 